\title{
The measurement of dorsal radial tilt by $x$-ray and computed tomography
}

\author{
(iD) Jingning $L i^{1}$ \\ Zhenjie $M a^{1}$ \\ Fei Gao \\ Yuan Ji
}

1. Department of Hand Surgery, Yantaishan Hospital, Yantai, Shangdong, China

\section{SUMMARY}

OBJECTIVE: We conducted this study to define and measure the dorsal radial tilt, and to guide the reduction of distal radius fractures and the pre-bending of steel plates used in surgery.

METHODS: The dorsal radial tilt was measured using both computed tomography (CT) and x-ray from both left and right side. The differences and correlations of the data measured by those two methods and from two sides were analyzed.

RESULTS: The tilts measured by $x$-ray were significantly bigger than those measured by CT from the left side $(t=55.51, p<0.01)$ and from the right side ( $t=49.81, p<0.01)$. The tilts measured by those two methods from the left and right sides were correlated $(r=0.85, p<0.01$; $r=0.81, p<0.01)$. The dorsal radial tilts measured from the left side were not significantly different from those measured from the right side by CT ( $t=1.49, p>0.05)$ and by $x$-ray $(t=1.51, p>0.05)$. The dorsal radial tilts measured from the left side by CT were significantly different from those measured from the right side by $x$-ray $(t=43.07, p<0.01)$, and these two sets of data were correlated $(r=0.71, p<$ $0.01)$. The dorsal radial tilts measured from the left side by $x$-ray was significantly different from that measured from right side by $C T$ $(t=40.43, p<0.01)$, and those two sets of data were also correlated $(r=0.75, p<0.01)$.

Conclusions: The dorsal radial tilts measured from one side by one method can be used to estimate the tilts measured from the other side / the same side by the same method / the other method.

KEYWORDS: Radius fractures. Tomography, X-ray computed. X-Rays.

\section{INTRODUCTION}

The forearm contains two bones of different sizes and the radius is the larger one. ${ }^{1}$ The distal end is the end that towards the wrist. The distal radius fracture is the fracture that happens at the region of the radius near the wrist. ${ }^{2}$ Distal radius fracture can happen in many different ways, but almost all the cases happened at the area about 1 inch from the end of the bone. Distal radius fracture, which is a common type of fracture, accounts for about $17 \%$ of all the cases of emergency fracture. ${ }^{3}$ The occurrence of distal radius fracture is usually followed by the displacement and deformity healing, which in turn affect the wrist function. ${ }^{4}$ In addition, distal radius fracture can cause the emergence of pain, limited rotation capacity, lower grip strength and other complications, which will reduce patients' quality of life. The dorsal radial tilt is one of the important factors that affect the prognosis of the fracture. ${ }^{5}$ However, no study on the measurement of dorsal radial tilt has been reported.

DATE OF SUBMISSION: 04-Feb-2018

DATE OF ACCEPTANCE: 25-Feb-2018

Corresponding Author: Jingning Li

Department of Hand Surgery, Yantaishan Hospital

liefang Road, 91, Zhifu District, Yantai, Shandong Province, China

Phone: 86-0535-6602176

E-mail: lijingning0129@126.com, lijingning2018@outlook.com 
X-ray and CT are two imaging systems that are widely used in medical diagnosis. ${ }^{6,7}$ The wavelength of x-ray ranges from 0.01 to 10 nanometers. X-ray imaging is based on the phenomena of the attenuation of the x-ray beam. That is, an x-ray can go through the body with part of the energy absorbed by the body, and this energy absorption can be detected by a detector on the opposite side of the body, resulting in clinical images. ${ }^{8}$ Conventional x-ray imaging can only produce a 2D image. While computed tomography, which is also called CT scanning, can produce 3D images by combing many images obtained from x-ray imaging taken in different directions, ${ }^{9}$ resulting in images with more information and information that is more accurate. In our study, the dorsal radial tilts of 50 healthy volunteers were measured using both CT and x-ray from both the left side and right side. The measured date from different sides and by different methods was analyzed and compared. We found that the tilts measured by $\mathrm{x}$-ray were bigger than those measured by CT. There was no significant difference in tilts measured by the same method from the different side, indicating the symmetric development of distal radius. In addition, the tilts of the distal radius measured by CT from one side were significantly different from the tilts measured by x-ray from the other side, and the two sets of data were correlated. Therefore, an x-ray can be used to measure the tilts of the distal radius and to estimate the tilts measured by CT, which can be used to provide an individualized treatment method for the patients with distal radius fractures.

\section{OBJECTS AND METHODS}

Grouping and processing of experimental objects

We discussed the research background, purpose, procedures, risks and benefits of this clinical trial in detail with the volunteers in this study and gave them sufficient time to consider carefully. All the patients signed the informed consent. The ethics committee of Yantaishan Hospital approved this study. This study was carried out from January 2016 to April 2016 at the Yantaishan Hospital.

50 cases of healthy adult volunteers were involved. The dorsal radial tilts of the 50 volunteers were measured both left side (50 cases) and right side (50 cases). The definition of dorsal radial tilts: the surface of the distal radius bone forms curve towards palm, and the angle formed by the distal and proximal bone is the dorsal radial tilt. The distal ra- dius bone was scanned by both x-ray and CT to measure the dorsal radial tilt.

\section{Specimen data collection and processing}

The dorsal radial tilt was measured by both x-ray and CT.

CT measurement. Philips Ingenuity 128-layer CT (CTMR room, Yantaishan Hospital) was used to perform sagittal tomography along the long axis of the bony outgrowths of the distal radius. CT imaging system measured the angle formed by the distal and proximal bone of the curve at the surface of the distal radius bone.

X-ray measurement. Philips multi-function digital photography system (department of radiology, Yantaishan Hospital) was used to take photos on specimen wrist with standard side position, and this system was also used to measure the angle formed by the distal and proximal bone of the curve at the surface of the distal radius bone.

The dorsal radial tilt measured from the same side by $\mathrm{x}$-ray and CT was statistically analyzed. The dorsal radial tilts measured by x-ray and CT from different sides were also statistically analyzed. In addition, the dorsal radial tilts measured from one side by CT was used to compare with the tilts measured from the other side by CT.

\section{Statistical analyses}

SPSS13.0 statistical software was used to analyze the measured data. The results of each group were expressed as the mean \pm standard deviation $(\overline{\mathrm{x}} \pm \mathrm{SD})$. The statistical analysis of the measurement results was carried out by the paired t-test and the correlation analysis of two variables.

\section{RESULTS}

Dorsal radial tilts measured by $\mathrm{x}$-ray and $\mathrm{CT}$ from two sides

The mean value of the dorsal radial tilt measured by CT was $29.12 \pm 1.95^{\circ}$ from the left side and 29.46 $\pm 2.18^{\circ}$ from the right side, and the tilt measured by $\mathrm{x}$-ray was $38.65 \pm 2.31^{\circ}$ from the left side and $38.96 \pm$ $2.23^{\circ}$ from the right side. The tilts measured by x-ray were significantly bigger than those measured by CT from the left side $(t=55.51, p<0.01)$, and the tilts measured by those two methods from the left side were correlated $(\mathrm{r}=0.85, p<0.01)$. The $95 \%$ confidence interval of angle difference is $\left(9.19^{\circ}, 9.88^{\circ}\right)$. The tilts mea- 
sured by $\mathrm{x}$-ray were significantly bigger than those measured by CT from the right side $(\mathrm{t}=49.81, p<0.01)$, and the tilts measured by those two methods from the right side were correlated $(\mathrm{r}=0.81, p<0.01)$. The 95\% confidence interval of angle difference is $\left(9.12^{\circ}, 9.89^{\circ}\right)$ (Table 1). These data suggest that the tilt measured by these two methods are different but correlated.

The comparison of tilts of dorsal radial tilt measured by $x$-ray from different sides and by CT from the different sides

There was no significant difference in the dorsal radial tilts measured by CT from different sides $(\mathrm{t}=1.49$, $p>0.05$ ), in addition, no significant difference in the tilts of distal radius measured by $\mathrm{x}$-ray from different sides was found ( $\mathrm{t}=1.51, p>0.05$ ) (Table 2 ).

The comparison between the dorsal radial tilt measured by CT from one side and the tilt measured by $\mathrm{x}$-ray from the other side

The dorsal radial tilts measured from the left side by CT were significantly different from those measured from the right side by $\mathrm{x}$-ray $(\mathrm{t}=43.07, p<0.01)$, and the $95 \%$ confidence interval of angle difference is $\left(9.38^{\circ}, 10.30^{\circ}\right)$. The dorsal radial tilts measured from the left side by $x$-ray were significantly different from those measured from the right by CT $(\mathrm{t}=40.43$, $p<0.01$ ), and the $95 \%$ confidence interval of angle difference is $\left(8.74^{\circ}, 9.65^{\circ}\right)$ (Table 3$)$. These data suggest that the tilt measured by one method from one side is different from the tilt measured by the other method from the other side.

TABLE 1 - THE COMPARISON TILTS OF DISTAL RADIUS MEASURED BY X-RAY AND CT FROM THE SAME SIDE

\begin{tabular}{l|l|l} 
Groups & \multicolumn{1}{l}{$\begin{array}{l}\text { Tilts measured by } \\
\mathrm{CT}\left({ }^{\circ}\right)\end{array}$} & $\begin{array}{l}\text { Tilts measured by } \\
x-\text { ray }\left({ }^{\circ}\right)\end{array}$ \\
\hline Left group & $29.12 \pm 1.95^{\dagger}$ & $38.65 \pm 2.31^{\dagger}$ \\
\hline Right group & $29.46 \pm 2.18^{\ddagger}$ & $38.96 \pm 2.23^{\ddagger}$ \\
\hline Left group t: $p<0.01$; right group $\neq: p<0.01$ &
\end{tabular}

TABLE 2 - THE COMPARISON OF DORSAL RADIAL TILTS MEASURED BY X-RAY FROM DIFFERENT SIDES AND BY CT FROM THE DIFFERENT SIDES

\begin{tabular}{l|l|l} 
Groups & \multicolumn{1}{l}{$\begin{array}{l}\text { Tilts measured by } \\
\mathrm{CT}\left({ }^{\circ}\right)\end{array}$} & $\begin{array}{l}\text { Tilts measured by } \\
x \text {-ray }\left(^{\circ}\right)\end{array}$ \\
\hline Left group & $29.12 \pm 1.95 \S$ & $38.65 \pm 2.31$ " \\
\hline Right group & $29.46 \pm 2.18 \S$ & $38.96 \pm 2.23 \rrbracket$ \\
\hline
\end{tabular}

Comparison of the tilts measured by CT from different sides $\xi$ : $p>0.05$; comparison of the tilts measured by $x$-ray from different sides $\boldsymbol{q}: p>0.05$
The comparison between the dorsal radial tilt measured by CT from the left side and the tilts measured by $\mathrm{x}$-ray from the right side aa: $p<0.01$; the comparison between the dorsal radial tilts measured by CT from the right side and the tilts measured by $\mathrm{x}$-ray from the left side aa: $p<0.01$.

The dorsal radial tilts measured from the left side by CT were correlated with the data measured from the right side by $\mathrm{x}$-ray $(\mathrm{r}=0.71, p<0.01)$, and the dorsal radial tilts measure from the left side by x-ray were also correlated with those measured from right by CT $(\mathrm{r}=0.75, p<0.01)$ (Table 4$)$. These data suggest that the tilt measured by one method from one side is correlated with the tilt measured by the other method from the other side.

The correlation between the dorsal radial tilts measured by CT from the left side and the tilts measured by $\mathrm{x}$-ray from the right side aa: $p<0.01$; the correlation between the dorsal radial tilts measured by CT from the right side and the tilts measured by $\mathrm{x}$-ray from the left side aa: $p<0.01$.

\section{DISCUSSION}

Distal radius fracture is a common type of fracture, accounting for about $17 \%$ of all the cases of emergency fracture. ${ }^{3}$ Distal radius fracture usually brings pain, limited rotation capacity, lower grip strength and other complications to the patients, which can affect the wrist function, reduce the patients' quality of life and bring heavy economic and psychological burdens to the patients and their fam-

TABLE 3 - THE COMPARISON BETWEEN THE TILTS OF THE DISTAL RADIUS MEASURED BY CT FROM ONE SIDE AND THE TILTS MEASURED BY X-RAY FROM THE OTHER SIDE

\begin{tabular}{l|l|l}
\multicolumn{1}{l}{ Groups } & \multicolumn{1}{l}{$\begin{array}{l}\text { Tilts measured by } \\
\mathrm{CT}\left({ }^{\circ}\right)\end{array}$} & $\begin{array}{l}\text { Tilts measured by } \\
x \text {-ray }\left(^{\circ}\right)\end{array}$ \\
\hline Left group & $29.12 \pm 1.95^{\dagger}$ & $38.65 \pm 2.31^{\ddagger}$ \\
\hline Right group & $29.46 \pm 2.18^{\ddagger}$ & $38.96 \pm 2.23^{\dagger}$ \\
\hline
\end{tabular}

TABLE 4 - THE CORRELATION BETWEEN THE DORSAL RADIAL TILTS MEASURED BY CT FROM ONE SIDE AND THE TILTS MEASURED BY X-RAY FROM THE OTHER SIDE

\begin{tabular}{l|l|l}
\multicolumn{1}{l}{ Groups } & \multicolumn{1}{l}{$\begin{array}{l}\text { Tilts measured by } \\
\text { CT }\left({ }^{\circ}\right)\end{array}$} & $\begin{array}{l}\text { Tilts measured by } \\
\text { x-ray }\left({ }^{\circ}\right)\end{array}$ \\
\hline Left group & $29.12 \pm 1.95^{\dagger}$ & $38.65 \pm 2.31^{\ddagger}$ \\
\hline Right group & $29.46 \pm 2.18^{\ddagger}$ & $38.96 \pm 2.23^{\dagger}$ \\
\hline
\end{tabular}


ily. ${ }^{10,11}$ The dorsal radial tilt, which is formed by the distal and proximal bone of the curve at the surface of the distal radius bone, is one of the important factors that affect the treatment as well as prognosis of patients with the fracture. ${ }^{5}$ Based on our knowledge, no study on the measurement of dorsal radial tilt has been reported. Therefore, this study was carried out to define and measure the dorsal radial tilt for purposes of providing a reference for the treatment. In our study, the dorsal radial tilts of 50 healthy volunteers were measured by both CT and $\mathrm{x}$-ray from both the left side and right side. We found that the mean value of the dorsal radial tilt measured by CT was $29.12 \pm 1.95^{\circ}$ from the left side and $29.46 \pm 2.18^{\circ}$ from the right side, and the tilt measured by x-ray from was $38.65 \pm 2.31^{\circ}$ from the left side and $38.96 \pm 2.23^{\circ}$ from the right side. The dorsal radial tilts measured by $\mathrm{x}$-ray were significantly bigger than those measured by CT from the left side $(\mathrm{t}=55.51, p<0.01)$, indicating that the outcomes of dorsal radial tilt measurement were different from different measurement methods. In addition, we also found that the tilts measured by those two different methods were different from each other but also correlated each other (Table 1). So the data measured by one method can be used to estimate the data measured by the other method.

In our study, no significant difference was found in the dorsal radial tilts measured from different side by CT $(\mathrm{t}=1.49, p>0.05)$ and by $\mathrm{x}$-ray $(\mathrm{t}=1.51, p>0.05)$ (Table 2), indicating the symmetric development of distal radius, so the dorsal radial tilt measured from either side can be used for clinical diagnosis. In addition, the dorsal radial tilts measured by CT from one side were used to compare the dorsal radial tilts measured by $\mathrm{x}$-ray from the other side, and the results showed that the dorsal radial tilts measured from the left side by CT were significantly different from those measured from right by $\mathrm{x}$-ray $(\mathrm{t}=43.07, p<0.01)$. In addition, the dorsal radial tilts measured from the left side by $\mathrm{x}$-ray were also significantly different from those measured from the right by CT $(\mathrm{t}=40.43, p<0.01)$ (Table 2). However, further analyses found that the dorsal radial tilts measured from the left side by CT was correlated with the data measured from right by $\mathrm{x}$-ray $(\mathrm{r}=0.71$, $p<0.01$ ), and the dorsal radial tilts measured from the left side by $x$-ray were also correlated with those measured from right by CT $(\mathrm{r}=0.75, p<0.01)$ (Table 4). Our data suggested that the dorsal radial tilts measured from one side by one method was significantly different from those measured from the other side by the other method, but they are still closely correlated with each other. Therefore, we think, in clinical practice, the dorsal radial tilts measured from one side by one method can be used to estimate the tilts measured from the other side/the same side by the same method/the other method. These findings in our study will facilitate the clinical measurement of dorsal radial tilts and the treatment and prognosis of patients with distal radius fractures, and it should be popularized in clinical practice.

\section{CONCLUSION}

In conclusion, the dorsal radial tilts measured by $\mathrm{x}$-ray were found to be bigger than those measured by CT from both sides. No significant difference was found in dorsal radial tilts measured by the same method from different sides, indicating the symmetric development of distal radius. The dorsal radial tilts measured by CT from one side were significantly different from the tilts measured by x-ray from the other side, and the two sets of data were correlated. Therefore, an x-ray can be used to measure the dorsal radial tilt, and the data got from x-ray can be used to estimate the tilts measured by CT, which will provide the basis for the individualized treatment of distal radius fractures.

\section{RESUMO}

OBJETIVO: Realizamos este estudo para definir e medir a inclinação radial dorsal, e para orientar a redução das fraturas do raio distal e a pré-flexão das chapas de aço utilizadas na cirurgia.

MÉTODOS: A inclinação radial dorsal foi medida usando tomografia computadorizada (TC) e raios $X$ dos lados esquerdo e direito. As diferenças e correlações dos dados medidos por esses dois métodos e de dois lados foram analisadas.

RESULTADOS: As inclinações medidas por raios X foram significativamente maiores que as medidas pela TC do lado esquerdo ( $t=55,51$, $p<0,01)$ e do lado direito $(t=49,81, p<0,01)$. As inclinações medidas por esses dois métodos dos lados esquerdo e direito foram correlacionadas $(r=0,85, p<0,01 ; r=0,81, p<0,01)$. As inclinações radiais dorsais medidas a partir do lado esquerdo não foram significativamente diferentes das medidas do lado direito por $C T(t=1,49, p>0,05)$ e por raios $X(t=1,51, p>0,05)$. As inclinações radiais dorsais medidas a partir do lado esquerdo por TC foram significativamente diferentes das medidas a partir do lado direito por raios $X(t=43,07, p<0,01)$, e 
esses dois conjuntos de dados foram correlacionados $(r=0,71, p<0,01)$. As inclinações radiais dorsais medidas a partir do lado esquerdo por raios $X$ foram significativamente diferentes das medidas do lado direito por $C T$ ( $t=40,43, p<0,01)$, e esses dois conjuntos de dados também foram correlacionados $(r=0,75, p<0,01)$.

CONCLUSÕES: As inclinações radiais dorsais medidas de um lado por um método podem ser usadas para estimar as inclinações medidas do outro lado/o mesmo lado pelo mesmo método/o outro método.

PALAVRAS-CHAVE: Fraturas do rádio. Tomografia computadorizada por raios X. Raios X.

\section{REFERENCES}

1. Burt LA, Naughton GA, Greene DA, Ducher G. Skeletal differences at the ulna and radius between pre-pubertal non-elite female gymnasts and non-gymnasts. J Musculoskelet Neuronal Interact. 2011;11(3):227-33.

2. Wolfe SW. Distal radius fractures. In: Wolfe S, Pederson W, Kozin SH, eds. Green's operative hand surgery. $6^{\text {th }}$ ed. Philadelphia: Churchill Livingstone; 2011. p.561-638.

3. Grewal R, MacDermid JC, King GJ, Faber KJ. Open reduction internal fixation versus percutaneous pinning with external fixation of distal radius fractures: a prospective, randomized clinical trial. J Hand Surg Am. 2011;36(12):1899-906.

4. Diaz-Garcia RJ, Oda T, Shauver MJ, Chung KC. A systematic review of outcomes and complications of treating unstable distal radius fractures in the elderly. J Hand Surg Am. 2011;36(5):824-35.

5. Arora R, Lutz M, Deml C, Krappinger D, Haug L, Gabl M. A prospective randomized trial comparing nonoperative treatment with volar locking plate fixation for displaced and unstable distal radial fractures in patients sixty-five years of age and older. J Bone Joint Surg Am. 2011;93(23):214653.

6. Moscariello A, Takx RA, Schoepf UJ, Renker M, Zwerner PL, O'Brien TX, et al. Coronary CT angiography: image quality, diagnostic accuracy, and potential for radiation dose reduction using a novel iterative image reconstruction technique-comparison with traditional filtered back projection. Eur Radiol. 2011;21(10):2130-8.

7. Avni U, Greenspan H, Konen E, Sharon M, Goldberger J. X-ray categorization and retrieval on the organ and pathology level, using patch-based visual words. IEEE Trans Med Imaging. 2011;30(3):733-46.

8. Baka N, Kaptein BL, de Bruijne M, van Walsum T, Giphart JE, Niessen WJ, et al. 2D-3D shape reconstruction of the distal femur from stereo $X$-ray imaging using statistical shape models. Med Image Anal. 2011;15(6):84050.

9. Herman GT. Fundamentals of computerized tomography: image reconstruction from projections. London: Springer Science \& Business Media; 2009. p.64-8

10. MacDermid JC, Donner A, Richards RS, Roth JH. Patient versus injury factors as predictors of pain and disability six months after a distal radius fracture. J Clin Epidemiol. 2002;55(9):849-54.

11. Arora R, Gabl M, Gschwentner M, Deml C, Krappinger D, Lutz M. A comparative study of clinical and radiologic outcomes of unstable colles type distal radius fractures in patients older than 70 years: nonoperative treatment versus volar locking plating. J Orthop Trauma. 2009;23(4):237-42. 